
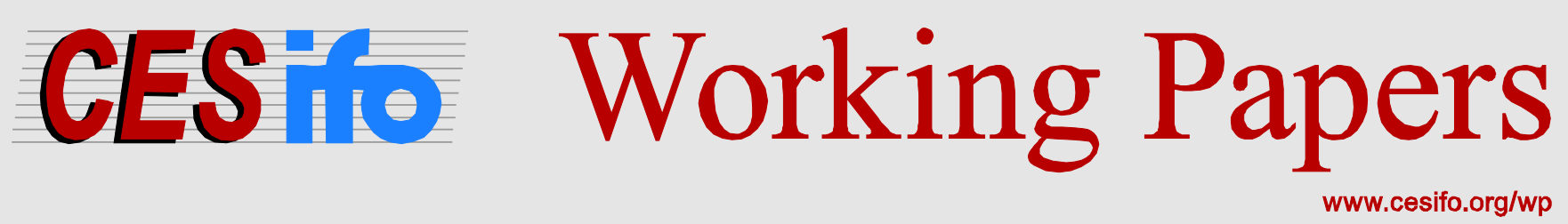

\title{
Pollution and City Size: Can Cities be too Small?
}

\author{
Rainald Borck \\ Takatoshi Tabuchi
}
CESIFO WORKING PAPER NO. 6152
CATEGORY 10: ENERGY AND CliMATE ECONOMICS
OCTOBER 2016

An electronic version of the paper may be downloaded

- from the SSRN website:

- from the RePEc website:

- from the CESifo website:

WWW.SSRN.com

Www.RePEc.org

www.CESifo-group.org/wp

\section{CESifo}




\title{
Pollution and City Size: Can Cities be too Small?
}

\begin{abstract}
We study the optimal and equilibrium size of cities in a city system model with environmental pollution. Pollution is related to city size through the effect of population on production, commuting, and housing consumption. With symmetric cities, if pollution is local or per capita pollution increases with population, we find that equilibrium cities are too large. When pollution is global and per capita pollution declines with city size, however, equilibrium cities may be too small. With asymmetric cities, the largest cities are too large and the smallest too small when pollution is local or per capita pollution increases with population; when pollution is global and per capita pollution decreases with population, the largest cities are too small and the smallest too large. We also calibrate the model to US cities and find that the largest cities may be undersized by 3-4\%.
\end{abstract}

JEL-Codes: R120, Q540.

Keywords: optimal city size distribution, agglomeration, pollution.

\author{
Rainald Borck \\ University of Potsdam \\ Faculty of Economic and Social Sciences \\ August-Bebel-Str. 89 \\ Germany - 14482 Potsdam \\ rainald.borck@uni-potsdam.de
}

\author{
Takatoshi Tabuchi \\ University of Tokyo \\ Faculty of Economics \\ Hongo 7-3-1, Bunkyo-ku \\ Tokyo / Japn \\ ttabuchi@e.u-tokyo.ac.jp
}

This version: October 14, 2016

We thank Stefan Bauernschuster, Jan Brueckner, M. Morikawa, T. Morita, Michael Pflüger, and M. Yano as well as participants at the ERSA/UEA meeting in Lisbon, the Verein für Socialpolitik meeting in Münster and its regional economics section in Dresden, the DP seminar at RIETI, and the Osaka spatial economics conference for comments and suggestions. The first author thanks the German Science Foundation (DFG) and the second author thanks RIETI for financial support. 


\section{Introduction}

Urbanization is rapidly increasing, especially in developing countries. According to the UN Population Division, urbanization worldwide will increase from $51.6 \%$ in 2010 to $66.4 \%$ in 2050, and from $46.1 \%$ to $63.4 \%$ in the developing world. Some commentators are afraid that this urbanization may have adverse environmental consequences. For instance, Seto et al. (2012) argue that the projected urbanization until 2030 leads to significant loss of biodiversity and increased $\mathrm{CO}_{2}$ emissions due to deforestation and land use changes. Urban economic activities such as manufacturing production, commuting, and residential energy use also contribute to pollution. Fig. 1 shows that over the last half century, urbanisation and $\mathrm{CO}_{2}$ emissions have moved together. Of course, this may not be a causal relation.

In fact, some writers who claim that large, densely populated cities produce lower per capita emissions. Glaeser and Kahn (2010) show that in the US, inhabitants of large, densely populated cities such as New York City and San Francisco tend to produce lower $\mathrm{CO}_{2}$ emissions from transport and residential energy use than those living in smaller and less densely populated cities, controlling for factors such as local weather. Glaeser (2011) writes about this Triumph of the City and in the subtitle succinctly states: "How our greatest invention makes us richer, smarter, greener, healthier, and happier" (our emphasis). This line of reasoning has prompted organizations such as the OECD and the World Bank to advocate high density urban development to mitigate environmental pollution.

Therefore, an important policy question is whether big cities are good or bad for the environment, especially in developing countries such as China, where new cities are springing up by the minute. While on the one hand, migrants flock to cities to take advantage of their economic opportunities, on the other hand, concern about congestion, environmental pollution and other side effects is mounting. So what is the optimal size of cities that are affected by environmental pollution? And what would be the unregulated equilibrium city size?

In this paper, we build a simple model of a city system to study how the equilibrium and optimal city size distribution is affected by environmental pollution. We use a standard monocentric city model, where people work, consume goods and housing in cities. Agglomeration externalities make workers more productive in big cities. Pollution is related to city size since it is a by-product of urban production, commuting and housing. We distinguish between pollution which is purely local, such as certain kinds of emissions from traffic, and pollution which spills over between cities, such as greenhouse gas (GHG) emissions. When 
cities are symmetric, we find that with local pollution, equilibrium cities are too large and there are too few of them, mirroring the classic result of Henderson (1974). By contrast, when pollution is global, we find that equilibrium cities may be either too small or too big. The former case can occur when per capita pollution falls with city size. We also study the model with a given number of asymmetric cities. With local pollution, we find that the largest cities are too large and the smallest cities too small. With global pollution, if per capita pollution decreases with city size and the marginal damage of pollution is large enough, the largest cities are too small and the smallest too large.

We also present a numerical simulation to gauge the possible divergence between optimal and equilibrium city size. Using data from Fragkias et al. (2013), we estimate the effect of the size of US metropolitan areas on $\mathrm{CO}_{2}$ emissions. We find that doubling city size reduces per capita $\mathrm{CO}_{2}$ emissions by 20 percent. In the symmetric city case, we find that cities might be undersized by up to 9 percent if pollution is global. With asymmetric cities, in the case of global pollution, the largest cities may be undersized by 3-4 percent while the smallest cities are oversized by 5-10 percent. If pollution is local, the largest cities are oversized, but by only about $0.3 \%$. Finally, we use an estimate of the degree of pollution spillovers (so pollution is neither completely global nor completely local) and find that the largest city is undersized by $2.4 \%$ and the smallest is oversized by $6.6 \%$.

Our paper is related to two strands of literature. First, the literature on city systems has studied equilibrium and optimal city sizes. Henderson (1974) first showed that in equilibrium, cities are too big. This finding also comes out of the models by Tolley (1974), Arnott (1979), and Abdel-Rahman (1988). On the other hand, some recent papers show that cities may be too small in equilibrium. Albouy and Seegert (2012) show that the introduction of taxes may lead to inefficiently small cities, and that if cities are heterogeneous, large cities may be too small. Eeckhout and Guner (2015) also show that spatially uniform taxation may lead to large cities being undersized, and that the optimum spatial tax system taxes individuals in large cities less than the current US tax system. ${ }^{1}$ Behrens and Robert-Nicoud (2015), on the other hand, show that allowing for heterogeneous sites may lead to the biggest cities being oversized. Like Albouy and Seegert (2012) and Eeckhout and Guner (2015), we show that cities may be too small. However, the mechanism in our paper, namely negative externalities from intercity pollution, is different.

Second, there is a small but growing literature on cities and the environment more

\footnotetext{
${ }^{1} \mathrm{Au}$ and Henderson (2006) show that many Chinese are too small due to the migration restrictions of the hukou system.
} 
general. Related to this paper, Gaigné et al. (2012) and Borck and Pflüger (2015) study the interaction of agglomeration, pollution and welfare in models with a given number (two) of cities. There are also some theoretical papers on urban structure and pollution, see Borck (2016), Borck and Brueckner (2016), Dascher (2014), Larson et al. (2012) and Tscharaktschiew and Hirte (2010). Finally, Glaeser and Kahn (2010) and Larson and Yezer (2015) study empirically the relation between GHG emissions or energy use and city structure. Glaeser and Kahn (2010) find that large, dense cities in the US produce fewer GHG emissions. Morikawa (2013) finds that dense cities in Japan produce lower per capita energy consumption in the service sector, and Blaudin de Thé and Lafourcade (2016) show that residents of low density suburban households use more gasoline for driving. Larson and Yezer (2015) study the effect of city size on energy use in a simulation model, finding that per capita energy use does not change with city size. A number of papers from other disciplines than economics also study the relation between city size and pollution empirically, with different results, e.g. Fragkias et al. (2013) and Sarzynski (2012). Our paper is also concerned with the relation between pollution and city size, which is essential for the comparison of equilibrium and optimal city systems.

We proceed as follows. The next section introduces the model of a symmetric city system. Section 3 presents the modeling of pollution. In section 4 , we study the equilibrium and optimum size of cities with local and global pollution. Section 5 contains a numerical simulation, to get a sense of the possible divergence of optimum and equilibrium city size. In Section 6, we extend both the analytical and simulation results to the realistic case of asymmetric cities. The last section concludes.

\section{The model with symmetric cities}

There are $m$ cities in the economy, whose total population is exogenous and denoted by $N$. For now, we assume cities to be identical. The population size in each city is endogenous and given by $n=N / m$. For simplicity, the city space is linear with unit width and the central business district (CBD) is a spaceless point located at $x=0$, while the endogenous city border is denoted $\bar{x}$ (we focus on the right side of the city for simplicity). All individuals commute to the CBD and have identical preference given by

$$
u(s, z, E)=s^{\alpha} z^{1-\alpha} E^{-\beta},
$$


and the budget constraint is

$$
w=z+r s+t x
$$

where $s$ is housing floor space (equivalently land consumption), $z$ is consumption of a composite non-housing good, $E$ is pollution, $w$ is wage income, $r$ is the housing rent per square meter, $t$ is the commuting cost per mile, $x$ is distance from the CBD, and $0<\alpha<1$, and $\beta>0$.

Consumers choose $s$ and $z$ to maximize (1) subject to (2). From this we get optimal housing consumption

$$
s(w-t x, r)=\frac{\alpha(w-t x)}{r} .
$$

Consumers are mobile within and between cities, and land is rented to the highest bidder. We can now solve for households' bid rent, i.e., the maximum amount the household would be willing to pay per unit of land. Using (3) and (2) in (1) and solving $u(z, s, E)=\bar{u}$ gives

$$
r(w-t x, E, v)=(w-t x)^{1 / \alpha} E^{-\beta / \alpha} v^{-1 / \alpha},
$$

where $v \equiv \alpha^{-\alpha}(1-\alpha)^{-(1-\alpha)} \bar{u}$.

The two equilibrium conditions in the representative city are:

$$
\begin{aligned}
r(w-t \bar{x}, E, v) & =r_{A} \\
\int_{0}^{\bar{x}} \frac{1}{s(w-t x, E, v)} d x & =n
\end{aligned}
$$

where $r_{A}$ is the agricultural land rent. Eq. (5) states that at the city border, land rent just equals the agricultural land rent. Eq. (6) says that the population $n$ fits into the city between 0 and $\bar{x}$.

Suppose that there are external economies of scale at the city level, for instance because of gains from individual specialization. Total city production is assumed to be $Y=n^{1+\gamma}$, with $0<\gamma<\alpha$ and the individual wage is $w=n^{\gamma}$. $^{2}$ Substituting (3) and (4) into (5) and (6) and solving gives the city border and indirect utility

$$
\begin{aligned}
& \bar{x}=\frac{n^{\gamma}\left[1-r_{A}^{\alpha}\left(r_{A}+t n\right)^{-\alpha}\right]}{t} \\
& v=n^{\gamma}\left(r_{A}+t n\right)^{-\alpha} E^{-\beta} .
\end{aligned}
$$

\footnotetext{
${ }^{2}$ Duranton and Puga (2004) show that several different mechanisms lead to the same functional form, such as gains from specialization, matching, sharing intermediate inputs, or learning.
} 
Eq. (7) shows that the city expands as population grows. Note that because of the separability of utility, $\bar{x}$ is not affected by pollution. Eq. (8) shows the standard tradeoff induced by an increasing city population: on the one hand, utility increases with $n$ due to agglomeration forces, on the other hand, it decreases because of longer commutes and competition for land, which results in higher land rents. In the next section, we model pollution in order to study how it affects this fundamental tradeoff. In particular, the pertinent question is how reallocating population among cities affects the disutility from pollution.

Note that we have assumed that land is owned by absentee landowners. As is well known, efficiency analysis requires returning differential land rents to city residents. We

show in Appendix C, however, that our results hold qualitatively if land is owned by city residents.

\section{Pollution}

Pollution in city $i$ is given by

$$
E_{i}=e\left(n_{i}\right)+\delta \sum_{j=1}^{m-1} e\left(n_{j}\right)
$$

where $e$ is local pollution and $0 \leq \delta \leq 1$ measures the degree of pollution spillovers. When $\delta=0$, pollution is purely local (for instance, some forms of particulate pollution which do not diffuse over long distances). Conversely, when $\delta=1$, pollution is purely global from the view of our city system, as is the case, for instance, for GHG emissions. Importantly, in the latter case, the environmental externality is independent of the individual's location.

An important issue in the coming analysis will be the relationship between pollution and city population. What do we know about this relation? In Section 5, we will try to estimate the population elasticity of pollution empirically, but here we briefly discuss theoretical an empirical studies that address this issue.

Borck and Pflüger (2015) present a theoretical model in which urban pollution is driven by commuting, residential energy use, industrial and agricultural production, and goods transport. They show that per capita pollution from industrial production and residential energy use decreases with city size, while pollution from commuting and goods transport increases. The total effect of city population on urban pollution depends on parameters.

Some authors have estimated the relation between pollution and city population (or 
population density) empirically. Most of these papers estimate an equation of the form $e=A n^{\theta}$, which we will also do in Section $5 .^{3}$ Lamsal et al. (2013) use cross-sectional cross-country data on $\mathrm{NO}_{2}$ and $\mathrm{NO}_{\mathrm{X}}$ pollution and find that the elasticity of pollution with respect to population density lies between 0.4 and 0.67. Gudipudi et al. (2016) study the effect of population density on $\mathrm{CO}_{2}$ emissions and find an elasticity around 0.6 , so doubling population density would reduce per-capita emissions by $40 \%$. Fragkias et al. (2013) also estimate the effect of population on $\mathrm{CO}_{2}$ emissions, using panel data from US cities. They find an elasticity of emissions with respect to population of 0.93. Rybski et al. (2016) conduct a meta-analysis of published articles that study $\mathrm{CO}_{2}$ emissions and city size, and find that in developed countries per capita emissions decrease with city size while in developing countries per capita emissions increase with city population. However, most of these estimates seem problematic. For instance, Lamsal et al. (2013) use crosssectional OLS regressions to estimate the population elasticity of pollution. But this ignores potential confounders that are correlated with population density and pollution. Fragkias et al. (2013) use panel data, but they estimate the model with random effects, which assumes that any unobserved time-invariant heterogeneity between cities is not correlated with pollution. In Section 5, we present an alternative estimate of the population elasticity of $\mathrm{CO}_{2}$ pollution, using the same dataset as Fragkias et al. (2013).

\section{Equilibrium and optimum number and size of cities}

The equilibrium city size in the city system is defined by the solution of $v_{i}=v^{*}$ for all $i$. We focus on symmetric cities. Further, we require the equilibrium to be stable, which implies $\partial v(n) / \partial n<0$. The optimal city size is found by maximizing $m n v(n)$ with respect to $n$ and $m$. Using $m n=N$, this is equivalent to maximizing $v(n)$ with respect to $n$. Note that, from (8) follows $v(0)=0$ so no one would ever want not to live in a city.

\footnotetext{
${ }^{3}$ Some papers not reviewed here estimate other functional forms, where, for instance, pollution is assumed to be a quadratic function of population.
} 


\subsection{Local pollution}

Suppose first that pollution is entirely local, i.e. $\delta=0$. Then migration is governed by the following utility differential

$$
\begin{aligned}
v\left(n_{i}\right)-v\left(n_{j}\right) & =\hat{v}\left(n_{i}\right) e\left(n_{i}\right)^{-\beta}-\hat{v}\left(n_{j}\right) e\left(n_{j}\right)^{-\beta}, \\
\text { where } \hat{v}(n) & \equiv n^{\gamma}\left(r_{A}+t n\right)^{-\alpha},
\end{aligned}
$$

and optimum city size maximizes $v\left(n_{i}\right)=\hat{v}\left(n_{i}\right) e\left(n_{i}\right)^{-\beta}$. We will assume that both $v(n)$ and $\hat{v}(n)$ are quasi-concave, which holds (in the neighborhood of the equilibrium and social optimum) for the parameter values used in our numerical simulations. Moreover, we assume that locally produced pollution $e\left(n_{i}\right)$ satisfies $e(0)=0$ and $d e / d n_{i}>0$.

Since $v\left(n_{i}\right)$ can be shown to be inverted U-shaped, we get the standard result that equilibrium cities are too large, as in Henderson (1974). This can be seen by looking at Fig. 2. The figure shows the optimal city size $\hat{n}$ and two potential equilibrium city sizes $\tilde{n}$ and $n^{e} .{ }^{4}$ Any equilibrium with city size $\tilde{n}<\hat{n}$ is unstable: if the city population were to deviate slightly from $\tilde{n}$, migration in or out of the city would occur, as indicated by the arrows. Conversely, any equilibrium with $n^{e}>\hat{n}$ is stable: as indicated by the arrows, a deviation from $n^{e}$ would induce migration flows which restore the equilibrium. Therefore, there is a continuum of equilibria with $n^{e}>\hat{n}$ where $\hat{n}=n^{*}$ maximizes $v\left(n_{i}\right)$. We summarize this as:

Proposition 1 If pollution is purely local, $\delta=0$, cities are too large in equilibrium.

\subsection{Global pollution}

Now, let $\delta=1$ so that pollution is global from the viewpoint of the economy. Since pollution is global, we can drop the index $i$ from pollution $E_{i}$ and write the utility difference of living in city $i$ versus $j$ as

$$
v\left(n_{i}\right)-v\left(n_{j}\right)=E^{-\beta}\left(\hat{v}\left(n_{i}\right)-\hat{v}\left(n_{j}\right)\right) .
$$

For $E>0$, the individual migration decision is determined by the difference $\hat{v}\left(n_{i}\right)-$ $\hat{v}\left(n_{j}\right)$, so global pollution does not affect migration decisions. Let $\hat{n}$ denote the city size

\footnotetext{
${ }^{4}$ Note that there is a continuum of equilibria, so all that can be said in general is that $n^{e}>\hat{n}$, but the exact location of the equilibrium is indeterminate.
} 
which solves $\max _{n} \hat{v}(n)$. Setting $\hat{v}^{\prime}(n)=0$ and solving gives

$$
\hat{n}=\frac{\gamma r_{A}}{(\alpha-\gamma) t}
$$

Then, by the same argument as in Henderson (1974), there is a continuum of stable equilibria with city sizes $n^{e}>\hat{n}$. Fig. 3 shows possible equilibrium city sizes. As before, any equilibrium with $n^{e}>\hat{n}$ is stable.

The optimum city size $n^{*}$ is found by maximizing $v(n)=\hat{v}(n) E(n)^{-\beta}$. The first order condition can be written

$$
\hat{v}^{\prime}(n)-\beta \hat{v}(n) \frac{E^{\prime}(n)}{E(n)}=0 .
$$

We know that $n^{e} \geq \hat{n}$ and that $\hat{n}$ maximizes $\hat{v}(n)$. Since $\beta>0, E(n)>0$ and $\hat{v}(n)$ is quasiconcave, evaluating (12) at $\hat{n}$ implies that $n^{*}<\hat{n}$ if $E^{\prime}(\hat{n})>0$. Since $E(n)=m \cdot e(n)=$ $\frac{N}{n} e(n)$, we find cities are definitely too large if per capita pollution is increasing in city size. Intuitively, in this case making cities larger increases pollution, which increases the disutility from pollution. This reinforces the argument in Henderson-style models which make cities too large.

However, if per capita emissions are decreasing in city size, we find $n^{*}>\hat{n}$. This opens up the possibility that in equilibrium, cities may be too small. However, since there is a continuum of equilibria with $n^{e}>\hat{n}$, cities may also be too large. Summarizing this discussion, we have:

Proposition 2 Suppose that pollution is global, i.e. $\delta=1$. If per capita emissions increase with $n$, cities are too large in equilibrium. However, if per capita emissions decrease with $n$, cities may be either too small or too large in equilibrium.

Fig. 3 illustrates the case where pollution is global and per capita emissions are decreasing with city size. The blue curve depicts the function $\hat{v}(n)$ and the equilibrium city size is some $n^{e}>\hat{n}$. The orange curve shows the curve $v(n)$ and the optimum city size is $n^{*}{ }^{5}$ The thick red part of the $v(n)$ curve shows the part where the possible equilibrium city size (with $n^{e}>\hat{n}$ ) is smaller than the optimum size. However, the equilibrium city size may also be larger than $n^{*}$.

As Prop. 2 makes clear, in the case of global emissions whether cities are over- or undersized depends on how per-capita emissions change with city population. However,

\footnotetext{
${ }^{5}$ The functions have been rescaled so that $v\left(n^{*}\right)=\hat{v}\left(n^{*}\right)$ for better visibility.
} 
as already stated in Section 3, not much is known about this relationship. Therefore, we estimate this relationship in the next section, where we use numerical simulation to gauge whether cities will be over- or undersized in equilibrium.

\section{Numerical simulation}

We now try to assess to what extent optimum and equilibrium city size may diverge, using numerical simulation. Suppose that total emissions in city $i$ in year $t$ are $e_{i t}=B n_{i t}^{\theta}$. Then, per capita emissions decrease with population size if and only if $\theta<1$.

We can then estimate a linear regression of the form

$$
\log e_{i t}=c+\theta \log n_{i t}+\varepsilon_{i t}
$$

where $c \equiv \log B$ is a constant, and $\varepsilon$ is the error term.

We use data from Fragkias et al. (2013) to estimate $\mathrm{CO}_{2}$-emissions in US core based statistical areas (metropolitan statistical areas and micropolitan areas) from 1999-2008. The dataset contains $\mathrm{CO}_{2}$ emissions and population for 933 core based statistical areas (CBSAs). Emissions are based on data from the Vulcan Project, which quantifies U.S. fossil fuel carbon dioxide emissions at $10 \mathrm{~km} \times 10 \mathrm{~km}$ grid cells and at the scale of individual factories, power plants, roadways and neighborhoods on an hourly basis. These are aggregated by Fragkias et al. (2013) to annual observations by CBSA.

If pollution were local, then our model would predict that individual migration decisions are based on city emissions, so population would be endogenous and OLS estimation would consequently be biased. Given that $\mathrm{CO}_{2}$ is a global pollutant, however, this is not a concern in the present setup, since migration should be independent of local emissions. We will try to mitigate estimation bias by adding various fixed effects to our baseline regression.

We start by estimating (13) by pooled OLS. Results are shown in column (1) of Tab. 1. Standard errors are clustered at the CBSA level. The coefficient on population is 0.938, and it is significantly smaller than one. This is a first indication that per capita pollution might be lower in larger cities.

Next, in column (2), we include time fixed effects to allow for any time varying factors that are common across CBSAs and affect emissions, such as national business cycles. If these cycles were correlated with population size (say because some cities grow more than others when the economy grows) and also affect $\mathrm{CO}_{2}$ emissions, the OLS coefficient would 
be biased. The coefficient in column (2), however, is the same as in the model without time effects.

In column (3) we include CBSA fixed effects. Some cities may have disproportionately many power plants that service larger geographic areas. Also, cities may differ in some unobserved dimension such as industry structure, climate, or other factors that may affect population size and emissions at the same time. As long as this heterogeneity is time invariant, we can control for it by estimating a model with CBSA fixed effects. As shown in column (3), the coefficient on population drops to 0.83 once we control for CBSA and time fixed effects. Thus, the result that $\theta<1$ does not seem to be driven by unobserved heterogeneity among CBSAs.

Finally, to control for potential macroeconomic effects that affect regions differentially and may be correlated with city size and emissions, in column (4), we include interaction effects between year and US census divisions (there are 4 census regions and 9 divisions). As can be seen from the Table, the coefficient on population slightly drops to 0.8, and it remains significantly smaller than one. ${ }^{6}$ Fig. 4 displays a binned scatter plot of log emissions against log population, controlling for CBSA as well as division by year fixed effects. Since this estimate controls extensively for time-varying regional heterogeneity, we will use this value of $\theta$ for the numerical simulation. However, we will also use the higher value of 0.94 as a robustness check.

We now want to compare (the smallest possible) equilibrium city size, $\hat{n}$ (see (11)), and optimal city size, $n^{*}$, which we now derive. Consider global emissions, $\delta=1$. Since $e=B n^{\theta}$, we have $E=m \cdot e=B N n^{\theta-1}$. Substituting in (8) gives

$$
v(n)=(B N)^{-\beta} n^{\gamma+(1-\theta) \beta}\left(r_{A}+t n\right)^{-\alpha} .
$$

Maximizing with respect to $n$ gives

$$
n^{*}=\frac{[\gamma+(1-\theta) \beta] r_{A}}{[\alpha-\gamma-(1-\theta) \beta] t} .
$$

We use the following parameter values. The expenditure share of housing is set to $\alpha=0.24$ (following Davis and Ortalo-Magné, 2011), the agglomeration elasticity is $\gamma=0.05$ (see Combes and Gobillon, 2015, for an overview), and the elasticity of pollution is set to

\footnotetext{
${ }^{6}$ The $p$-values for the test for $\theta<1$ are: 0.0001 in column (1), 0.0001 in column (2), 0.045 in column (3) and .0499 in column (4). In all cases, the hypothesis that $\theta<1$ cannot be rejected at the $5 \%$ significance level.
} 
$\theta=0.8$, following our regression results.

The maximum divergence between optimal and equilibrium city size, $n^{*}-\hat{n}$, is increasing in $\beta$, the index of the marginal damage of pollution. In the Appendix, we calibrate $\beta$, using central estimates of the social cost of carbon from the literature. Using the central estimate of USD 40.54 per metric ton $\mathrm{CO}_{2}$ for 2015 (assuming 3\% discounting, value updated to 2015 USD) from the recent study by Interagency Working Group on Social Cost of Carbon (2015), we find a value of $\beta=0.022 .^{7}$ We then get a maximum divergence of $n^{*} / \hat{n}=1.1137$. Again, while cities could be oversized in equilibrium, this suggests they could be undersized by up to 11.4 percent. If $\theta=0.94$, the optimal city size could exceed the equilibrium size by up to $3.5 \%$.

At the high end of estimates of the social cost of carbon, we use the 95th percentile estimate of USD 118 for 2015 from Interagency Working Group on Social Cost of Carbon (2015) (again at 3\% discounting, in 2015 USD), which gives a value of $\beta=0.064$. In this case (using the original $\theta=0.8$ ), we find $n^{*} / \hat{n}=1.347$, so the optimum city size could exceed the equilibrium size by as much as 35 percent. Finally, estimates for the social cost of carbon increase over time. For 2050, the central and 95th percentile values from Interagency Working Group on Social Cost of Carbon (2015) are USD 77.70 and 238.74. The implied values for $\beta$ are 0.042 and 0.13 . Then, optimal city size could exceed equilibrium city size by up to $22 \%$ in the first and $76 \%$ in the second case. Furthermore, since climate change damages are estimated to increase over time, our model predicts that if global pollution leads to cities that are too large, the severity of the problem should increase over time.

\section{Asymmetric cities}

\subsection{Equilibrium and social optimum with asymmetric city sizes}

We now introduce asymmetric cities into the model. To do so, we assume that an individual living in city $i$ obtains utility

$$
v_{i}\left(n_{i}\right)=A_{i} n_{i}^{\gamma}\left(r_{A}+t n_{i}\right)^{-\alpha} E_{i}^{-\beta}
$$

\footnotetext{
7 The study reports averages over three different integrated assessment models. We use their average value across the three models for 2015 at 3\% discounting, USD 36 or EUR 40.54, as our central value.
} 
The variable $A_{i}$ is a city level amenity, which could be a consumption amenity such as good weather or a production amenity such as good infrastructure or a favourable geographic location. Without loss of generality, we assume $A_{1}=1$ and $A_{i}>A_{i+1}$ for $i=1,2, \ldots, m-1$.

As before, pollution is given by

$$
E_{i}(\mathbf{n})=e\left(n_{i}\right)+\delta \sum_{j \neq i} e\left(n_{j}\right)
$$

with $e=n^{\theta}, \theta>0$.

We will assume the number of cities $m$ is fixed and then ask how the optimum allocation of population among these cities differs from the equilibrium one. Let $\hat{v}$ be the equilibrium utility level that is attained under free migration and let the equilibrium population vector be $\hat{\mathbf{n}}=\left\{\hat{n_{1}}, \ldots, \hat{n_{m}}\right\}$. The equilibrium city size distribution satisfies $v_{i}(\hat{\mathbf{n}})=v_{1}(\hat{\mathbf{n}})=v$ for all $i=1, \ldots, m$. Using $(16)$ and setting $A_{1}=1$, we can then solve for the amenity levels that are compatible with a free migration equilibrium:

$$
A_{i}=\left(\frac{\hat{n}_{1}}{\hat{n}_{i}}\right)^{\gamma}\left(\frac{r_{A}+t \hat{n}_{i}}{r_{A}+t \hat{n}_{1}}\right)^{\alpha}\left(\frac{E_{i}(\hat{\mathbf{n}})}{E_{1}(\hat{\mathbf{n}})}\right)^{\beta} .
$$

Note that our formulation implies that the amenity levels are uniquely identified by the equilibrium distribution of population up to the normalization that $A_{1}=1$.

We want to compare the equilibrium city size distribution to the optimal distribution. To characterize the latter, we assume the social planner maximizes the sum of utilities

$$
\max _{\mathbf{n}} \sum_{i=1}^{m} n_{i} v_{i}(\mathbf{n})
$$

subject to the population constraint $\sum_{i=1}^{m} n_{i}=N$. Letting $\lambda$ be the Lagrangean multiplier on the population constraint, the first order conditions are given by ${ }^{8}$

$$
v_{i}+n_{i} \frac{\partial v_{i}}{\partial n_{i}}+\sum_{j \neq i} n_{j} \frac{\partial v_{j}}{\partial n_{i}}=\lambda, \quad i=1, \ldots, m
$$

The last term on the LHS of (18) shows the pollution spillovers between cities.

The sign of $v_{i}-v_{i+1}$ is important in the following analysis. While $v_{i}=v_{i+1}$ holds at the equilibrium, suppose $v_{i}>v_{i+1}$ holds for all $i$ at the social optimum. Because $\partial v_{i} / \partial n_{i}$

\footnotetext{
${ }^{8}$ We assume an interior solution where $0<n_{i}^{*}<N$ for all $i$ and that the second order conditions hold.
} 
is negative in the neighborhood of a stable equilibrium for almost all $i{ }^{9}$ it must be that the optimum $n_{i}$ is smaller than the equilibrium $n_{i}$ in large cities, whereas the optimum $n_{i}$ is larger than the equilibrium $n_{i}$ in small cities. The opposite is true when $v_{i}<v_{i+1}$. Therefore, we can now show the following:

Proposition 3 Assume that $\theta<1$. Then (i) if pollution is close to local, the optimal utility is higher in larger cities. Large cities are too large and small cities are too small at the equilibrium; (ii) if pollution is close to global and the marginal damage of pollution is sufficiently large, the optimal utility is lower in larger cities. Large cities are too small and small cities are too large at the equilibrium.

Proof. See Appendix B.

The intuition is as follows. Suppose that pollution is local, as might be the case, say, for $\mathrm{NO}_{\mathrm{X}}$. Then, the indirect utility $v_{i}$ is a function of its city size $n_{i}$ only. As shown by Henderson (1974), the indirect utility is decreasing in $n_{i}$ at a stable equilibrium.

Start from the equilibrium $v_{i}=v_{i+1}$ with $n_{i}>n_{i+1}$ and consider the effect of moving one person from the larger city $i$ to the smaller city $i+1$. The utility $v_{i}$ rises to $v_{i}+\Delta_{i}$ whereas the utility $v_{i+1}$ falls to $v_{i+1}-\Delta_{i+1}$ because $v_{i}$ decreases with $n_{i}$. The rise $\Delta_{i}$ and fall $\Delta_{i+1}$ are similar in magnitude when the one person is sufficiently small relative to total city size. Since there are more people in city $i$, however, the sum of $n_{i} \Delta_{i}$ exceeds the sum of $n_{i+1} \Delta_{i+1}$. Therefore, it is optimal to reduce the size of larger cities and raise that of smaller cities. As a result, the utility levels in larger cities are higher than those in smaller cities at the optimum.

By contrast, if pollution is global, such as in the case of $\mathrm{CO}_{2}$, concentrating population in bigger cities decreases total emissions if $\theta<1$, which benefits residents in all cities. When moving one person from a smaller city $i+1$ to a larger city $i$, utility of city $i$ residents falls while that of $i+1$ residents rises. However, due to the global externality, utility of the residents of all other cities also rises. Therefore, as long as the marginal damage of pollution is large enough, social welfare rises.

Examining (18) in Appendix B, we can further say the following. Given sufficiently large $\delta$ (i.e., close to global pollution), large cities are more likely to be too small if the housing expenditure share $\alpha$, the agricultural land rent $r_{A}$, and the commuting cost $t$ are small. In this case, the crowding effects induced by commuting and tight housing markets

\footnotetext{
${ }^{9}$ Tabuchi and Zeng (2004) show that a stable equilibrium requires $\partial v_{i} / \partial n_{i}<0$ for at least $M-1$ cities.
} 
in larger cities are outweighed by the beneficial effect of reduced pollution for all other cities.

In order to correct the discrepancy between the equilibrium and optimal distributions of city sizes, the national government may impose location taxes and subsidies according to city size. In the case of global pollution with $\theta<1$, in our setup, living in large cities should be subsidized to make them more attractive. ${ }^{10}$

\subsection{Simulation}

We now simulate numerically the equilibrium and optimal city size distribution with asymmetric cities. We will pursue two different simulation exercises. In both of these, we assume a given number of cities, $m$, and given total population $N$. So we exclude the formation of new cities.

We then compare the equilibrium number of cities to the social optimum. The first exercise will assume that the population distribution among the cities follows Zipf's law, while the second uses a sample of the actual city size distribution among US CBSAs.

In both exercises, we use the same parameter values, partly already described in Section 5. In particular, we set $\alpha=0.24, \gamma=0.05, \theta=0.8$, and $\beta=0.022$. The rest of the parameters are as follows. From Borck and Brueckner (2016), we set $r_{A}=\$ 58,800$, the annual land rent of agricultural land in the US, and $t=\$ 503$, the annual (monetary plus time) commuting cost per mile in the US. Further, we set the number of cities to 180. For the actual US city size distribution, we use the 180 largest CBSAs. The total population is the sum of the population sizes of these 180 cities, $n=225,678,243$.

City size distribution under Zipf's law. In the first exercise, we assume that the city size distribution follows Zipf's law. As is well known, this is a good approximation for city systems in most countries, except at the very top and bottom of the distribution (Gabaix, 2016). With $n=225,678,243$, the largest city has 39 mill. inhabitants, the second largest 19.5 mill. and the smallest city has 217,180 inhabitants. We compute the amenity levels from (17) for these given population sizes.

We first assume $\delta=1$ so pollution is global. Fig. 5 shows the city size distribution using Zipf's law in blue and the optimal distribution in orange. For better visibility, the figure plots the equilibrium and optimal distributions assuming $\beta=0.1$. While the two

\footnotetext{
${ }^{10}$ See also Eeckhout and Guner (2015) for an analysis of taxes related to city size.
} 
distributions with $\beta=0.022$ are close, the biggest city is undersized by $3.5 \%$ while the smallest one is oversized by $7.7 \%$. The welfare gain from moving to the optimal city size distribution is small, less than $0.1 \%$ of income. ${ }^{11}$

When pollution is purely local, $\delta=0$, we find that the divergence between optimal and equilibrium city sizes is small, for given $\beta .^{12}$ The largest city is oversized by about $0.2 \%$ and the smallest city is undersized by $1.6 \%$.

The degree of spillovers, $\delta$, is obviously an important factor in determining whether cities are under- or oversized. Therefore, a natural question to ask is, what is the actual degree of spillovers from local emissions? To approach this question, we borrow from Borck and Brueckner (2016) who consider optimal energy taxation with local and global emissions. Assuming local and global emissions are equally valued, their parameters imply that local emissions make up $60.7 \%$ of emissions from commuting and $53 \%$ of emissions from residential energy use. Let us take the average of these values, $57 \%$, so we set $\delta=1-0.57=0.43$. We then find that the largest city is undersized by $2.5 \%$ and the smallest is oversized by $6.9 \%$. In the past two decades local pollution has decreased relative to global pollution and this trend is likely to continue (see, e.g., Amann et al., 2013). Moreover, the damage from global warming is projected to increase over time, since GHGs accumulate in the atmosphere and warming is caused by the stock of pollution. Therefore, we tentatively conclude that using realistic parameters, the case for large cities being undersized and small ones oversized persists and will get stronger over time.

Actual US city size distribution. We now redo the exercise using cities from the actual US city size distribution. Out of all MSAs (micropolitan areas are dropped) in the year 2008, we keep the largest 180 cities (see Tab. A.1 in the Appendix). These cities comprise $90 \%$ of the total population living in MSAs (252 mill.) and $80 \%$ of the population in CBSAs (283 mill.).

We assume that the current distribution is an equilibrium and, again, compute the amenities according to (17) (see Tab. A.1 in the Appendix). Fig. 5 again shows the equilibrium and optimal distribution. Zipf's law holds fairly well for the upper tail of the distribution. Note that the largest city in the sample, New York, has 18.7 mill. whereas

\footnotetext{
${ }^{11}$ When population is efficiently allocated, total emissions fall by $0.9 \%$, relative to the equilibrium. Note, however, that the welfare gain from efficiently allocating population in the absence of pollution would also be small with our parameters.

${ }^{12}$ We note that this is partly due to the assumption that the value of $\beta$ is the same for local and global pollution, but local pollution is much smaller than global pollution. Therefore, for a more realistic simulation, the marginal damage of local emissions relative to global emissions should probably be increased.
} 
according to Zipf's law the largest city has more than twice that many inhabitants. As shown in Fig. 5 and Tab. A.1, the three largest cities are undersized by 3.5-3.8\%. ${ }^{13}$ At the social optimum, the largest city in the sample, New York, is undersized by 696,211 of its 18.7 mill. inhabitants, while the second largest, Los Angeles, is undersized by 483,187. The smallest city in the sample is oversized by about $6.2 \%$. Note that out of the 180 cities, 28 are undersized and the other 152 are oversized at the equilibrium. In total, moving from the equilibrium to the optimal allocation would require moving 5.3 mill. people or $2.4 \%$ of the total population.

Sensitivity. We now briefly describe how the results change when we vary some of the model parameters. We concentrate on the case of global pollution and the distribution obtained by Zipf's law. First, we increase $\theta$ to 0.94 to reflect a potentially higher pollution elasticity. We find that the largest city is undersized by $1.6 \%$ and the smallest oversized by $3.8 \%$. Conversely, when $\theta$ decreases to 0.75 , the biggest city is undersized by $4.4 \%$ and the smallest city is oversized by $12.5 \%$. Since the benefit of concentration is increased the more per capita pollution decreases with city size, this finding is intuitive.

Next, suppose that in line with a high estimate of the social cost of carbon, the emissions damage, $\beta$, increases from 0.022 to 0.064 (see Section 5). Now, the largest city is undersized by $14.5 \%$ and the smallest oversized by $23 \%$. When the agglomeration elasticity, $\gamma$, increases from 0.05 to 0.08 , agglomeration becomes more efficient, and again, concentration increases at the optimum: the largest city is undersized by $4.5 \%$ at the equilibrium and the smallest oversized by $10 \% .^{14}$

On the other hand, increasing agricultural land rent $r_{A}$ to $\$ 100,000$ per year increases the costs of agglomeration. The effect on the optimum size of cities is rather small, however. A very similar result obtains when the per mile commuting cost increases to $\$ 750$ per year.

\section{Conclusion}

The paper has analyzed the optimum size of cities in an urban model with environmental pollution. When pollution is purely local and cities are symmetric, we find that equilibrium

\footnotetext{
${ }^{13}$ Again, the figure plots the two distributions using the largest 180 cities and $\beta=0.1$ to better show the difference between the two distributions.

${ }^{14}$ In fact, Tabuchi and Yoshida (2000) show that agglomeration externalities from consumption in Japanese cities are about the same size as productive externalities.
} 
cities are too large, mirroring the finding of Henderson (1974) and others. With asymmetric cities, this translates into the result that big cities are oversized and small cities undersized.

However, when pollution is global and per capita pollution decreases in population size, we find that in a symmetric city model, cities might be inefficiently small, contrary to the standard model. When cities are asymmetric, big cities are undersized and small cities oversized. Over the last decades, global pollution has increased relative to local pollution, and the damage from global warming increases over time. Hence, we conclude that for the future, a policy which favors big cities might actually be warranted.

Some possibilities for future research suggest themselves. First, our analysis was based on one estimate of the population elasticity of pollution, which is a central parameter in the analysis. More robust evidence on this parameter clearly seems important. Second, we think it would be interesting to redo the quantitative analysis with data from different countries. For instance, there is a growing number of papers on Chinese cities (e.g. Au and Henderson, 2006). Since the properties of the equilibrium city system and pollution patterns in China and other developing economies is undoubtedly different from developed countries, studying equilibrium and optimum city systems in this context would seem to be relevant. 


\section{Appendix}

\section{A Calibration of $\beta$}

We now calibrate $\beta$ using central estimates of the social cost of carbon from Interagency Working Group on Social Cost of Carbon (2015). The MRS between pollution and (nonhousing) consumption is

$$
\mathrm{MRS}=-\frac{\partial u / \partial E}{\partial u / \partial z}=\frac{\beta z}{(1-\alpha) E} .
$$

Substituting optimal consumption, $z(y)=(1-\alpha)(w-t x)$ gives MRS $=\beta(w-t x) / E$, and integrating over the city gives citywide MRS

$$
\begin{aligned}
\overline{\mathrm{MRS}} & =\int_{0}^{\bar{x}} \frac{\beta(w-t x)}{E} \frac{1}{s(x)} d x \\
& =\frac{\beta w\left[t n+r_{A}-r_{A}^{1+\alpha}\left(t n+r_{A}\right)^{-\alpha}\right]}{(1+\alpha) t E} .
\end{aligned}
$$

where we have substituted the optimal $s(x)$ and used (7) and (8). Finally, letting $M$ be world population and $n$ be city population, we get the social cost of carbon

$$
\mathrm{SCC}=\frac{\beta M w\left[t n+r_{A}-r_{A}^{1+\alpha}\left(t n+r_{A}\right)^{-\alpha}\right]}{(1+\alpha) t n E} .
$$

We use the following parameters: world population in 2015 was $M=7.35$ billion (source: UN World Population Prospects, http://esa.un.org/unpd/wpp/Download/Standard/Population/), world per capita income in 2015 was $w=\$ 10,743$ (source: UN National Accounts Main Aggregates Database, http://unstats.un.org/unsd/snaama/dnllist.asp), and total $\mathrm{CO}_{2}$ emissions were $E=34,649$ million metric tons $\mathrm{CO}_{2}$ in 2011 (source: World Bank, World Development Indicators, http://data. worldbank. org/indicator/EN. ATM. CO2E. KT/countries). We set $n=750,000$ and from Borck and Brueckner (2016), we use $t=\$ 503.53, \alpha=0.24$, and $r_{A}=\$ 58,800$.

The target value for the social cost of carbon is USD 40.54 per ton $\mathrm{CO}_{2}$, using the central value from Interagency Working Group on Social Cost of Carbon (2015) (converted from 2007 to 2015 USD). Using the stated parameters, setting (A.4) equal to 40.54 and solving gives $\beta=0.022$. The other values in the text are solved likewise using different values for the social cost of carbon. 


\section{B Proofs}

Proof of Proposition 3. Since

$$
\begin{aligned}
n_{i} \frac{\partial v_{i}}{\partial n_{i}} & =\gamma v_{i}-\frac{\alpha t n_{i}}{r_{A}+t n_{i}} v_{i}-\beta \theta n_{i}^{\theta} v_{i} E_{i}^{-1} \\
\sum_{j \neq i} n_{j} \frac{\partial v_{j}}{\partial n_{i}} & =-\beta \theta \delta n_{i}^{\theta-1} \sum_{j \neq i} n_{j} v_{j} E_{j}^{-1}
\end{aligned}
$$

we have

$$
\begin{aligned}
& v_{i}+n_{i} \frac{\partial v_{i}}{\partial n_{i}}+\sum_{j \neq i} n_{j} \frac{\partial v_{j}}{\partial n_{i}}-\lambda \\
& =\left(1+\gamma-\frac{\alpha t n_{i}}{r_{A}+t n_{i}}\right) v_{i}-\beta(1-\delta) \theta v_{i} n_{i}^{\theta} E_{i}^{-1}-\beta \delta \theta Z n_{i}^{\theta-1}-\lambda \\
& =X_{i} v_{i}-\beta \delta \theta Z n_{i}^{\theta-1}-\lambda \\
& =0
\end{aligned}
$$

where

$$
X_{i} \equiv 1+\gamma-\frac{\alpha t n_{i}}{r_{A}+t n_{i}}-\beta(1-\delta) \theta n_{i}^{\theta} E_{i}^{-1}
$$

and $Z \equiv \sum_{j} n_{j} v_{j} E_{j}^{-1}$ is constant across cities.

Since the expression (A.5) is the same for $i$ and for $i+1$, we can eliminate $\lambda$ as follows:

$$
X_{i} v_{i}-\beta \delta \theta Z n_{i}^{\theta-1}=X_{i+1} v_{i+1}-\beta \delta \theta Z n_{i+1}^{\theta-1}
$$

which can be rewritten as

$$
v_{i}=\frac{1}{X_{i}}\left(X_{i+1} v_{i+1}+\beta \delta \theta Z n_{i}^{\theta-1}-\beta \delta \theta Z n_{i+1}^{\theta-1}\right) .
$$

Thus, the utility differential is

$$
\begin{aligned}
\Delta v & \equiv v_{i}-v_{i+1} \\
& =\frac{1}{X_{i}}\left[\left(X_{i+1}-X_{i}\right) v_{i+1}+\beta \delta \theta Z\left(n_{i}^{\theta-1}-n_{i+1}^{\theta-1}\right)\right] \\
& =\Delta V_{a}+\Delta V_{b},
\end{aligned}
$$


where

$$
\begin{aligned}
\Delta V_{a} & \equiv \frac{\alpha t r_{A} v_{i+1}\left(n_{i}-n_{i+1}\right)}{\left(r_{A}+t n_{i}\right)\left(r_{A}+t n_{i+1}\right)} \\
\Delta V_{b} & \equiv \beta \theta\left[(1-\delta) v_{i+1}\left(n_{i}^{\theta} E_{i}^{-1}-n_{i+1}^{\theta} E_{i+1}^{-1}\right)+\delta Z\left(n_{i}^{\theta-1}-n_{i+1}^{\theta-1}\right)\right] .
\end{aligned}
$$

While $\Delta V_{a}>0$, the sign of $\Delta V_{b}$ is indeterminate. However, the first term of $\Delta V_{b}$ is positive whereas the second term of $\Delta V_{b}$ is negative because

$$
\begin{aligned}
n_{i}^{\theta} E_{i}^{-1}-n_{i+1}^{\theta} E_{i+1}^{-1} & =\frac{1}{E_{i} E_{i+1}}\left(n_{i}^{\theta} E_{i+1}-n_{i+1}^{\theta} E_{i}\right) \\
& =\frac{\delta}{E_{i} E_{i+1}}\left(n_{i}^{\theta}-n_{i+1}^{\theta}\right) \sum_{j} n_{j}^{\theta}>0
\end{aligned}
$$

and

$$
n_{i}^{\theta-1}-n_{i+1}^{\theta-1}<0, \forall \theta \in(0,1)
$$

(i) Let $\delta=0$. Then, $\Delta V_{b}>0$, and thus $\Delta v>0$. By continuity, this also holds for $\delta$ positive but close to zero.

(ii) Let $\delta=1$. Solving $\Delta v<0$ for $\beta$, we have

$$
\Delta v<0 \Leftrightarrow \beta>\tilde{\beta} \equiv \frac{\alpha t r_{A} v_{i+1}\left(n_{i+1}-n_{i}\right)}{\theta Z\left(r_{A}+t n_{i}\right)\left(r_{A}+t n_{i+1}\right)\left(n_{i}^{\theta-1}-n_{i+1}^{\theta-1}\right)}>0 .
$$

By continuity, $\Delta v<0$ holds for sufficiently large $\beta$ when $\delta$ is close to but smaller than one.

\section{Local landownership}

Suppose that all land in a city is owned by residents, so the total differential land rent is distributed equally to all residents. Let income be given by $y=w+R / n$, where

$$
R=\int_{0}^{\bar{x}}\left(r(x, v)-r_{A}\right) d x
$$


is the total differential land rent. Rewriting (8) and (7) gives

$$
\begin{aligned}
& \bar{x}=\frac{(w+R / n)\left[1-r_{A}^{\alpha}\left(r_{A}+t n\right)^{-\alpha}\right]}{t} \\
& v=(w+R / n)\left(r_{A}+t n\right)^{-\alpha} E^{-\beta} .
\end{aligned}
$$

Substituting from (A.8) into $r(x, v)=(w+R / n-t x)^{1 / \alpha} E^{-\beta / \alpha} v^{-1 / \alpha}$ with $w=n^{\gamma}$ gives $r(x, v)=\left(r_{A}+t n\right)\left(n^{\gamma}+R / n\right)^{-1 / \alpha}\left(n^{\gamma}+R / n-t x\right)^{\frac{1}{a}}$. Using this in (A.6) and solving gives

$$
R=\frac{n^{1+\gamma}\left[r_{A}^{1+\alpha}-\left(r_{A}+t n\right)^{\alpha}\left(r_{A}-\alpha t n\right)\right]}{\left(r_{A}+t n\right)^{1+\alpha}-r_{A}^{1+\alpha}}
$$

Finally, substituting in (A.8) gives

$$
v=\frac{(1+\alpha) t E^{-\beta} n^{1+\gamma}}{\left(r_{A}+t n\right)^{1+\alpha}-r_{A}^{1+\alpha}}
$$

which is also inverted U-shaped in $n$.

We then redo the simulation exercise from Section 6.2. For the city size distribution described by Zipf's law with $\delta=1$, we find the largest city is undersized by $3.6 \%$ and the smallest is oversized by $7.3 \%$, so results are very close to the baseline simulation. Varying $\delta$ shows that this also holds for local pollution and for the intermediate case $\delta=0.43$.

\section{References}

Abdel-Rahman, H.M. (1988). Product differentiation, monopolistic competition and city size. Regional Science and Urban Economics 18, 69-86.

Albouy, D.Y. and N. Seegert (2012). The optimal population distribution across cities and the private-social wedge. Processed, University of Illinois and University of Utah.

Amann, M., Klimont, Z. and F. Wagner (2013). Regional and Global Emissions of Air Pollutants: Recent Trends and Future Scenarios. Annual Review of Environment and Resources 38, 31-55.

Arnott, R. Optimal city size in a spatial economy. Journal of Urban Economics 6, 65-89.

Au, C.C. and J.V. Henderson (2006). Are Chinese Cities Too Small? Review of Economic Studies 73, 549-576. 
Behrens, K. and F. Robert-Nicoud (2015). Are cities too small? Equilibrium and optimal urban systems with heterogeneous land. Mimeographed.

Blaudin de Thé, C. and M. Lafourcade (2016). The carbon footprint of suburbanization: Evidence from French household data. Mimeographed.

Borck, R. (2016). Will skyscrapers save the planet? Building height limits and urban greenhouse gas emissions. Regional Science and Urban Economics 58, 13-25.

Borck, R. and J.K. Brueckner (2016). Optimal energy taxation in cities. CESifo working paper 5711 .

Borck, R. and M. Pflüger (2015). Green cities? Urbanization, trade and the environment. IZA discussion paper 9104.

Combes, P.-P. and L. Gobillon (2015). The empirics of agglomeration economies. In G. Duranton, J. V. Henderson and W. C. Strange (eds.), Handbook of Regional and Urban Economics vol. 5, 247-348, Amsterdam: Elsevier.

Dascher, K. (2014). City Silhouette, World Climate. Available at http: //ssrn. com/abstract=2250673.

Davis, M.A. and F. Ortalo-Magné (2011). Household expenditures, wages, rents. Review of Economic Dynamics 14, 248-261.

Duranton, G. and D. Puga (2004). Micro-foundations of urban agglomeration economies, in J.V. Henderson and J.-F. Thisse (eds.), Handbook of Regional and Urban Economics, vol.4, 2063-2117, Amsterdam: Elsevier.

Eeckhout, J. and N. Guner (2015). Optimal Spatial Taxation: Are Big Cities Too Small? IZA DP No. 8781.

Fragkias, M., J. Lobo, Strumsky, D., and K.C. Seto (2013). Does size matter? Scaling of CO2 emissions and U.S. urban areas. PLoS ONE 8(6): e64727. doi: 10.1371/journal.pone.0064727

Gabaix, X. (2016). Power laws in economics: An introduction. Journal of Economic Perspectives 30, 185-206. 
Gaigné, C., Riou, S., and Thisse, J.-F. (2012). Are compact cities environmentally friendly? Journal of Urban Economics 72, 123-136.

Glaeser, E. (2011). Triumph of the City: How Our Greatest Invention Makes Us Richer, Smarter, Greener, Healthier, and Happier, New York: Penguin Press.

Glaeser, E.L. and Kahn, M.E. (2010). The greenness of cities: Carbon dioxide emissions and urban development. Journal of Urban Economics 67, 404-418.

Gudipudi, R., Fluschnik, T., Garcìa Cantú Ros, A., Walther, C., Kropp, J.P. (2016). City density and CO2 efficiency, Energy Policy 91, 352-361.

Henderson, J.V. (1974). The sizes and types of cities. American Economic Review 64, 640-656.

Interagency Working Group on Social Cost of Carbon, United States Government (2015). Technical Support Document: Technical Update of the Social Cost of Carbon for Regulatory Impact Analysis Under Executive Order 12866. US Government Printing Office, Washington D.C.

Lamsal, L.N., Martin, R.V., Parrish, D.D. and Krotkov, N.A. (2013). Scaling Relationship for NO2 Pollution and Urban Population Size: A Satellite Perspective. Environmental Science \&3 Technology 47, 7855-7861.

Larson, W. and Yezer, A.M. (2015). The energy implications of city size and density. Journal of Urban Economics 90, 35-49

Larson, W., Liu, F., and Yezer, A. (2012). Energy footprint of the city: Effects of urban land use and transportation policies. Journal of Urban Economics 72, 147-159.

Morikawa, M. (2013). Population density and efficiency in energy consumption: An empirical analysis of service establishments. Energy Economics 34, 1617-1622.

Rybski, D. Reusser, D.E., Winz, A.-L., Fichtner, C., Sterzel, T. Kropp, J.P. (2016). Cities as nuclei of sustainability? Environment and Planning B, first published on May 5, 2016, doi:10.1177/0265813516638340.

Sarzynski, A. (2012). Bigger Is Not Always Better: A Comparative Analysis of Cities and their Air Pollution Impact. Urban Studies 49, 3121-3138. 
Seto, K.C., Güneralp, B., and Hutyra, L.R. (2012). Global forecasts of urban expansion to 2030 and direct impacts on biodiversity and carbon pools. Proceedings of the National Academy of Sciences 109, 16083-6088.

Tabuchi, T. and Yoshida, A. (2000). Separating urban agglomeration economies in consumption and production. Journal of Urban Economics 48, Pages 70-84.

Tabuchi, T. and Zeng, D.-Z. (2004). Stability of spatial equilibrium. Journal of Regional Science 44, 641-660.

Tolley, G.S. (1974). The welfare economics of city bigness. Journal of Urban Economics 1, 324-345.

Tscharaktschiew, S. and Hirte, G. (2010). The drawbacks and opportunities of carbon charges in metropolitan areas - a spatial general equilibrium approach. Ecological Economics $70,339-357$. 


\section{Tables}

Table 1: $\mathrm{CO}_{2}$-emissions and city size

\begin{tabular}{lrrrr}
\hline & $(1)$ & $(2)$ & $(3)$ & $(4)$ \\
\hline Log population & $0.938^{* * *}$ & $0.938^{* * *}$ & $0.834^{* * *}$ & $0.802^{* * *}$ \\
& $(0.0168)$ & $(0.0168)$ & $(0.0978)$ & $(0.120)$ \\
Constant & $2.335^{* * *}$ & $2.343^{* * *}$ & $3.533^{* * *}$ & $3.896^{* * *}$ \\
& $(0.202)$ & $(0.201)$ & $(1.117)$ & $(1.369)$ \\
& & & & \\
Observations & 9,330 & 9,330 & 9,330 & 9,330 \\
R-squared [within] & 0.681 & 0.682 & 0.128 & 0.147 \\
\# of CBSAs & 933 & 933 & 933 & 933 \\
\hline Year fixed effects & No & Yes & Yes & Yes \\
CBSA fixed effects & No & No & Yes & Yes \\
Division $\times$ Year fixed effects & No & No & No & Yes \\
\hline
\end{tabular}

Standard errors are clustered at the CBSA level.

${ }^{* * *} p<0.01,{ }^{* *} p<0.05,{ }^{*} p<0.1$.

Source: own calculations based on data from Fragkias et al. (2013). 
Table A.1: Amenity levels and population for MSAs

\begin{tabular}{|c|c|c|c|c|c|}
\hline Rank & MSA & Amenity & Population & Optimal population & Emissions \\
\hline 1 & New York-Northern New Jersey-Long Island, NY-NJ-PA & 1 & 18672355 & 19368566 & 40.6523 \\
\hline 2 & Los Angeles-Long Beach-Santa Ana, CA & 0.929283 & 12692740 & 13175927 & 24.523 \\
\hline 3 & Chicago-Joliet-Naperville, IL-IN-WI & 0.877468 & 9384555 & 9712021 & 42.6155 \\
\hline 4 & Dallas-Fort Worth-Arlington, TX & 0.809967 & 6158022 & 6309423 & 17.4737 \\
\hline 5 & Philadelphia-Camden-Wilmington, PA-NJ-DE-MD & 0.803586 & 5906917 & 6044590 & 15.9336 \\
\hline 6 & Houston-Sugar Land-Baytown, TX & 0.79822 & 5702270 & 5828906 & 24.0447 \\
\hline 7 & Miami-Fort Lauderdale-Pompano Beach, FL & 0.791515 & 5454633 & 5568153 & 12.6531 \\
\hline 8 & Washington-Arlington-Alexandria, DC-VA-MD-WV & 0.789769 & 5391607 & 5501839 & 19.3482 \\
\hline 9 & Atlanta-Sandy Springs-Marietta, GA & 0.782982 & 5152141 & 5250104 & 25.4191 \\
\hline 10 & Boston-Cambridge-Quincy, MA-NH & 0.762562 & 4483141 & 4549310 & 13.6544 \\
\hline 11 & Detroit-Warren-Livonia, MI & 0.757858 & 4339504 & 4399464 & 18.7855 \\
\hline 12 & San Francisco-Oakland-Fremont, CA & 0.754658 & 4243932 & 4299907 & 17.8689 \\
\hline 13 & Riverside-San Bernardino-Ontario, CA & 0.750194 & 4113447 & 4164183 & 11.8552 \\
\hline 14 & Phoenix-Mesa-Glendale, AZ & 0.749949 & 4106372 & 4156830 & 14.1292 \\
\hline 15 & Seattle-Tacoma-Bellevue, WA & 0.721702 & 3355042 & 3380652 & 7.92053 \\
\hline 16 & Minneapolis-St. Paul-Bloomington, MN-WI & 0.716596 & 3231982 & 3254448 & 20.0776 \\
\hline 17 & San Diego-Carlsbad-San Marcos, CA & 0.707513 & 3022116 & 3039814 & 8.18351 \\
\hline 18 & St. Louis, MO-IL & 0.696989 & 2792889 & 2806143 & 20.9905 \\
\hline 19 & Tampa-St. Petersburg-Clearwater, FL & 0.694798 & 2746981 & 2759424 & 10.9384 \\
\hline 20 & Baltimore-Towson, MD & 0.691538 & 2679819 & 2691115 & 10.236 \\
\hline 21 & Denver-Aurora-Broomfield, CO & 0.680593 & 2463971 & 2471789 & 8.03722 \\
\hline 22 & Pittsburgh, PA & 0.674867 & 2356802 & 2362930 & 16.1156 \\
\hline 23 & Portland-Vancouver-Hillsboro, OR-WA & 0.664527 & 2172853 & 2175941 & 5.03929 \\
\hline 24 & Cincinnati-Middletown, OH-KY-IN & 0.660888 & 2110942 & 2112924 & 13.3771 \\
\hline 25 & Sacramento-Arden-Arcade-Roseville, CA & 0.660731 & 2108310 & 2110244 & 5.86701 \\
\hline 26 & Orlando-Kissimmee-Sanford, FL & 0.659487 & 2087489 & 2089037 & 6.3697 \\
\hline 27 & Cleveland-Elyria-Mentor, OH & 0.659344 & 2085110 & 2086614 & 12.8774 \\
\hline 28 & San Antonio-New Braunfels, TX & 0.657905 & 2061275 & 2062328 & 9.96783 \\
\hline 29 & Kansas City, MO-KS & 0.654128 & 1999739 & 1999578 & 12.7061 \\
\hline 30 & Las Vegas-Paradise, NV & 0.648598 & 1912349 & 1910333 & 6.01372 \\
\hline 31 & Columbus, $\mathrm{OH}$ & 0.641184 & 1800052 & 1795400 & 4.55883 \\
\hline 32 & San Jose-Sunnyvale-Santa Clara, CA & 0.640857 & 1795231 & 1790460 & 4.66359 \\
\hline 33 & Indianapolis-Carmel, IN & 0.635581 & 1718784 & 1712050 & 6.0172 \\
\hline 34 & Charlotte-Gastonia-Rock Hill, NC-SC & 0.634421 & 1702338 & 1695167 & 6.24345 \\
\hline 35 & Virginia Beach-Norfolk-Newport News, VA-NC & 0.631211 & 1657491 & 1649102 & 6.02219 \\
\hline 36 & Austin-Round Rock-San Marcos, TX & 0.629492 & 1633870 & 1624828 & 5.41536 \\
\hline 37 & Providence-New Bedford-Fall River, RI-MA & 0.6271 & 1601459 & 1591510 & 6.24221 \\
\hline 38 & Nashville-Davidson-Murfreesboro-Franklin, TN & 0.623012 & 1547259 & 1535778 & 6.90834 \\
\hline 39 & Milwaukee-Waukesha-West Allis, WI & 0.62232 & 1538232 & 1526495 & 6.60184 \\
\hline 40 & Jacksonville, FL & 0.604728 & 1322728 & 1305326 & 7.28384 \\
\hline 41 & Memphis, TN-MS-AR & 0.602921 & 1302060 & 1284213 & 5.0071 \\
\hline 42 & Louisville-Jefferson County, KY-IN & 0.599561 & 1264314 & 1245729 & 9.11605 \\
\hline 43 & Richmond, VA & 0.597203 & 1238353 & 1219325 & 6.56015 \\
\hline 44 & Oklahoma City, OK & 0.5952 & 1216645 & 1197290 & 4.88706 \\
\hline 45 & Hartford-West Hartford-East Hartford, CT & 0.59406 & 1204436 & 1184917 & 3.19058 \\
\hline 46 & Buffalo-Niagara Falls, NY & 0.587531 & 1136364 & 1116194 & 5.46278 \\
\hline 47 & Birmingham-Hoover, AL & 0.585626 & 1117101 & 1096833 & 13.5128 \\
\hline
\end{tabular}

continued on next page 
Tab. A.1 continued

\begin{tabular}{|c|c|c|c|c|c|}
\hline Rank & MSA & Amenity & Population & Optimal population & Emissions \\
\hline 48 & New Orleans-Metairie-Kenner, LA & 0.58529 & 1113736 & 1093455 & 7.66965 \\
\hline 49 & Salt Lake City, UT & 0.58297 & 1090691 & 1070352 & 2.91391 \\
\hline 50 & Raleigh-Cary, NC & 0.581589 & 1077163 & 1056816 & 2.53995 \\
\hline 51 & Rochester, NY & 0.578769 & 1049950 & 1029640 & 2.7185 \\
\hline 52 & Tucson, AZ & 0.569877 & 967778 & 947942 & 2.41114 \\
\hline 53 & Tulsa, OK & 0.564017 & 916525 & 897130 & 7.0816 \\
\hline 54 & Fresno, CA & 0.563209 & 909630 & 890294 & 2.05444 \\
\hline 55 & Bridgeport-Stamford-Norwalk, CT & 0.562524 & 903824 & 884536 & 3.17886 \\
\hline 56 & Albany-Schenectady-Troy, NY & 0.558009 & 866282 & 847263 & 2.93617 \\
\hline 57 & Albuquerque, NM & 0.557653 & 863383 & 844380 & 2.50765 \\
\hline 58 & New Haven-Milford, CT & 0.556821 & 856622 & 837655 & 2.3126 \\
\hline 59 & Omaha-Council Bluffs, NE-IA & 0.555393 & 845119 & 826202 & 6.44558 \\
\hline 60 & Dayton, $\mathrm{OH}$ & 0.555115 & 842897 & 823988 & 2.5307 \\
\hline 61 & Bakersfield-Delano, CA & 0.552004 & 818327 & 799464 & 4.98675 \\
\hline 62 & Allentown-Bethlehem-Easton, PA-NJ & 0.551455 & 814050 & 795187 & 5.04325 \\
\hline 63 & Oxnard-Thousand Oaks-Ventura, CA & 0.550461 & 806353 & 787482 & 2.29419 \\
\hline 64 & Worcester, MA & 0.548434 & 790847 & 771934 & 2.7666 \\
\hline 65 & Baton Rouge, LA & 0.548028 & 787767 & 768841 & 10.3903 \\
\hline 66 & Grand Rapids-Wyoming, MI & 0.546107 & 773342 & 754334 & 2.1559 \\
\hline 67 & El Paso, TX & 0.545649 & 769930 & 750898 & 2.64812 \\
\hline 68 & Columbia, SC & 0.54235 & 745740 & 726483 & 3.47064 \\
\hline 69 & McAllen-Edinburg-Mission, TX & 0.541094 & 736694 & 717330 & 3.53499 \\
\hline 70 & Greensboro-High Point, NC & 0.537515 & 711405 & 691688 & 1.98387 \\
\hline 71 & Akron, $\mathrm{OH}$ & 0.536347 & 703300 & 683456 & 1.9205 \\
\hline 72 & North Port-Bradenton-Sarasota, FL & 0.535276 & 695944 & 675982 & 2.82686 \\
\hline 73 & Springfield, MA & 0.534587 & 691239 & 671200 & 2.20756 \\
\hline 74 & Knoxville, TN & 0.534101 & 687939 & 667846 & 3.10894 \\
\hline 75 & Little Rock-North Little Rock-Conway, AR & 0.533206 & 681888 & 661696 & 2.15732 \\
\hline 76 & Stockton, CA & 0.531682 & 671692 & 651334 & 1.37026 \\
\hline 77 & Poughkeepsie-Newburgh-Middletown, NY & 0.530894 & 666468 & 646027 & 2.85408 \\
\hline 78 & Syracuse, NY & 0.529746 & 658913 & 638356 & 1.90001 \\
\hline 79 & Toledo, $\mathrm{OH}$ & 0.528919 & 653518 & 632882 & 3.62579 \\
\hline 80 & Charleston-North Charleston-Summerville, SC & 0.527387 & 643613 & 622844 & 6.73385 \\
\hline 81 & Greenville-Mauldin-Easley, SC & 0.524335 & 624245 & 603276 & 1.33841 \\
\hline 82 & Colorado Springs, CO & 0.523759 & 620644 & 599649 & 2.63146 \\
\hline 83 & Cape Coral-Fort Myers, FL & 0.5222 & 610984 & 589940 & 2.26724 \\
\hline 84 & Wichita, KS & 0.521918 & 609250 & 588200 & 2.19355 \\
\hline 85 & Boise City-Nampa, ID & 0.520933 & 603218 & 582158 & 1.66843 \\
\hline 86 & Lakeland-Winter Haven, FL & 0.519544 & 594801 & 573751 & 4.2558 \\
\hline 87 & Youngstown-Warren-Boardman, OH-PA & 0.515521 & 570952 & 550096 & 1.85198 \\
\hline 88 & Scranton-Wilkes-Barre, PA & 0.513898 & 561548 & 540839 & 1.64199 \\
\hline 89 & Madison, WI & 0.513254 & 557854 & 537214 & 3.79531 \\
\hline 90 & Des Moines-West Des Moines, IA & 0.512516 & 553644 & 533089 & 1.66703 \\
\hline 91 & Augusta-Richmond County, GA-SC & 0.510892 & 544471 & 524128 & 1.76162 \\
\hline 92 & Palm Bay-Melbourne-Titusville, FL & 0.510518 & 542378 & 522088 & 1.73565 \\
\hline 93 & Harrisburg-Carlisle, PA & 0.510505 & 542301 & 522013 & 1.60903 \\
\hline 94 & Jackson, MS & 0.508897 & 533371 & 513325 & 1.76857 \\
\hline 95 & Ogden-Clearfield, UT & 0.50803 & 528603 & 508696 & 1.43869 \\
\hline
\end{tabular}

continued on next page 
Tab. A.1 continued

\begin{tabular}{|c|c|c|c|c|c|}
\hline Rank & MSA & Amenity & Population & Optimal population & Emissions \\
\hline 96 & Chattanooga, TN-GA & 0.506223 & 518778 & 499172 & 1.75345 \\
\hline 97 & Portland-South Portland-Biddeford, ME & 0.505369 & 514191 & 494730 & 2.03088 \\
\hline 98 & Lancaster, PA & 0.504952 & 511957 & 492567 & 1.29977 \\
\hline 99 & Modesto, CA & 0.504402 & 509032 & 489735 & 1.16168 \\
\hline 100 & Provo-Orem, UT & 0.502238 & 497639 & 478699 & 1.77947 \\
\hline 101 & Deltona-Daytona Beach-Ormond Beach, FL & 0.502186 & 497366 & 478435 & 2.63952 \\
\hline 102 & Durham-Chapel Hill, NC & 0.500749 & 489919 & 471207 & 6.31914 \\
\hline 103 & Santa Rosa-Petaluma, CA & 0.497435 & 473091 & 454792 & 1.00393 \\
\hline 104 & Winston-Salem, NC & 0.49695 & 470666 & 452414 & 11.8863 \\
\hline 105 & Lansing-East Lansing, MI & 0.495532 & 463638 & 445499 & 2.25539 \\
\hline 106 & Spokane, WA & 0.495253 & 462263 & 444141 & 1.01927 \\
\hline 107 & Lexington-Fayette, KY & 0.494814 & 460112 & 442016 & 1.74198 \\
\hline 108 & Fayetteville-Springdale-Rogers, AR-MO & 0.492019 & 446592 & 428569 & 2.30046 \\
\hline 109 & Pensacola-Ferry Pass-Brent, FL & 0.491768 & 445392 & 427368 & 3.2278 \\
\hline 110 & Flint, MI & 0.489157 & 433082 & 414988 & 1.24379 \\
\hline 111 & York-Hanover, PA & 0.488364 & 429399 & 411263 & 3.27711 \\
\hline 112 & Springfield, MO & 0.48834 & 429289 & 411151 & 1.91169 \\
\hline 113 & Visalia-Porterville, CA & 0.488339 & 429283 & 411145 & 0.993425 \\
\hline 114 & Corpus Christi, TX & 0.48701 & 423168 & 404944 & 2.30819 \\
\hline 115 & Reno-Sparks, NV & 0.486071 & 418892 & 400598 & 1.44999 \\
\hline 116 & Port St. Lucie, FL & 0.485769 & 417520 & 399203 & 3.52693 \\
\hline 117 & Asheville, $\mathrm{NC}$ & 0.485755 & 417457 & 399139 & 1.62034 \\
\hline 118 & Santa Barbara-Santa Maria-Goleta, CA & 0.485401 & 415859 & 397513 & 1.10609 \\
\hline 119 & Fort Wayne, IN & 0.484556 & 412062 & 393650 & 1.24676 \\
\hline 120 & Mobile, AL & 0.483914 & 409196 & 390734 & 4.38011 \\
\hline 121 & Vallejo-Fairfield, CA & 0.483864 & 408972 & 390506 & 0.919361 \\
\hline 122 & Reading, PA & 0.483586 & 407737 & 389250 & 1.64164 \\
\hline 123 & Canton-Massillon, $\mathrm{OH}$ & 0.483226 & 406140 & 387627 & 0.815015 \\
\hline 124 & Salinas, CA & 0.483199 & 406022 & 387507 & 6.0969 \\
\hline 125 & Huntsville, AL & 0.482368 & 402361 & 383789 & 0.921342 \\
\hline 126 & Manchester-Nashua, NH & 0.481728 & 399556 & 380946 & 1.02811 \\
\hline 127 & Brownsville-Harlingen, TX & 0.480217 & 393000 & 374325 & 0.597551 \\
\hline 128 & Shreveport-Bossier City, LA & 0.48007 & 392367 & 373688 & 4.37908 \\
\hline 129 & Killeen-Temple-Fort Hood, TX & 0.480039 & 392237 & 373558 & 0.760663 \\
\hline 130 & Beaumont-Port Arthur, TX & 0.478403 & 385248 & 366560 & 2.958 \\
\hline 131 & Salem, OR & 0.478126 & 384075 & 365392 & 0.797142 \\
\hline 132 & Davenport-Moline-Rock Island, IA-IL & 0.476313 & 376467 & 357875 & 1.57889 \\
\hline 133 & Peoria, IL & 0.476196 & 375982 & 357400 & 5.41263 \\
\hline 134 & Montgomery, AL & 0.474808 & 370249 & 351811 & 1.38011 \\
\hline 135 & Trenton-Ewing, NJ & 0.473305 & 364119 & 345908 & 1.47235 \\
\hline 136 & Hickory-Lenoir-Morganton, NC & 0.473276 & 364003 & 345797 & 3.91189 \\
\hline 137 & Tallahassee, FL & 0.472592 & 361238 & 343158 & 1.25284 \\
\hline 138 & Fayetteville, NC & 0.47121 & 355712 & 337923 & 0.625336 \\
\hline 139 & Evansville, IN-KY & 0.47118 & 355591 & 337809 & 11.4147 \\
\hline 140 & Wilmington, NC & 0.47015 & 351517 & 333978 & 2.30292 \\
\hline 141 & Rockford, IL & 0.469747 & 349937 & 332497 & 1.19932 \\
\hline 142 & Eugene-Springfield, OR & 0.469298 & 348176 & 330849 & 0.676484 \\
\hline 143 & Ann Arbor, MI & 0.4676 & 341595 & 324696 & 1.09276 \\
\hline
\end{tabular}

continued on next page 
Tab. A.1 continued

\begin{tabular}{|c|c|c|c|c|c|}
\hline Rank & MSA & Amenity & Population & Optimal population & Emissions \\
\hline 144 & Savannah, GA & 0.465921 & 335185 & 318682 & 2.38122 \\
\hline 145 & Ocala, FL & 0.464557 & 330052 & 313817 & 0.756947 \\
\hline 146 & Kalamazoo-Portage, MI & 0.462754 & 323363 & 307368 & 0.97173 \\
\hline 147 & South Bend-Mishawaka, IN-MI & 0.461827 & 319966 & 304033 & 0.824083 \\
\hline 148 & Naples-Marco Island, FL & 0.460912 & 316641 & 300723 & 0.876601 \\
\hline 149 & Kingsport-Bristol-Bristol, TN-VA & 0.458516 & 308069 & 291989 & 2.22917 \\
\hline 150 & Roanoke, VA & 0.457814 & 305596 & 289423 & 1.89997 \\
\hline 151 & Charleston, WV & 0.457286 & 303743 & 287491 & 5.37228 \\
\hline 152 & Green Bay, WI & 0.456921 & 302468 & 286158 & 1.79404 \\
\hline 153 & Utica-Rome, NY & 0.455888 & 298886 & 282408 & 0.782581 \\
\hline 154 & Lincoln, NE & 0.455124 & 296258 & 279661 & 1.54115 \\
\hline 155 & Fort Smith, AR-OK & 0.454625 & 294551 & 277884 & $2.8656 \mathrm{~S}$ \\
\hline 156 & Fort Collins-Loveland, $\mathrm{CO}$ & 0.453771 & 291650 & 274888 & 1.28267 \\
\hline 157 & Boulder, CO & 0.453537 & 290859 & 274078 & 1.11593 \\
\hline 158 & Columbus, GA-AL & 0.452384 & 286985 & 270166 & 0.692666 \\
\hline 159 & Huntington-Ashland, WV-KY-OH & 0.452378 & 286966 & 270147 & 1.67665 \\
\hline 160 & Spartanburg, SC & 0.450172 & 279673 & 263115 & 0.778184 \\
\hline 161 & Erie, PA & 0.44987 & 278686 & 262200 & 0.781988 \\
\hline 162 & Duluth, MN-WI & 0.449832 & 278561 & 262085 & 2.29038 \\
\hline 163 & Lubbock, TX & 0.448545 & 274389 & 258312 & 0.940169 \\
\hline 164 & Atlantic City-Hammonton, NJ & 0.448117 & 273014 & 257093 & 0.864827 \\
\hline 165 & Norwich-New London, CT & 0.447998 & 272634 & 256757 & 0.803810 \\
\hline 166 & Lafayette, LA & 0.446242 & 267053 & 251818 & 0.942161 \\
\hline 167 & San Luis Obispo-Paso Robles, CA & 0.446021 & 266358 & 251191 & 0.799599 \\
\hline 168 & Hagerstown-Martinsburg, MD-WV & 0.445851 & 265823 & 250705 & 1.13058 \\
\hline 169 & Holland-Grand Haven, MI & 0.444596 & 261906 & 247000 & 3.57025 \\
\hline 170 & Gainesville, FL & 0.444525 & 261685 & 246781 & 1.13324 \\
\hline 171 & Clarksville, TN-KY & 0.444475 & 261530 & 246628 & 4.90448 \\
\hline 172 & Myrtle Beach-North Myrtle Beach-Conway, SC & 0.444177 & 260609 & 245701 & 1.01244 \\
\hline 173 & Santa Cruz-Watsonville, CA & 0.442845 & 256520 & 241318 & 0.62579 \\
\hline 174 & Cedar Rapids, IA & 0.442511 & 255503 & 240164 & 0.920119 \\
\hline 175 & Binghamton, NY & 0.441528 & 252527 & 236721 & 0.868548 \\
\hline 176 & Merced, CA & 0.440866 & 250538 & 234484 & 0.747178 \\
\hline 177 & Lynchburg, VA & 0.440451 & 249299 & 233199 & 0.971995 \\
\hline 178 & Bremerton-Silverdale, WA & 0.439647 & 246912 & 231226 & 0.399646 \\
\hline 179 & Amarillo, TX & 0.438812 & 244454 & 230499 & 3.3003 \\
\hline 180 & Olympia, WA & 0.438771 & 244332 & 229276 & 0.467105 \\
\hline
\end{tabular}

Note: The table displays population and emissions levels by MSA for 2008 from Fragkias et al. (2013).

Amenity levels are computed from (17); optimal population levels are simulated as described in the text. 


\section{Figures}

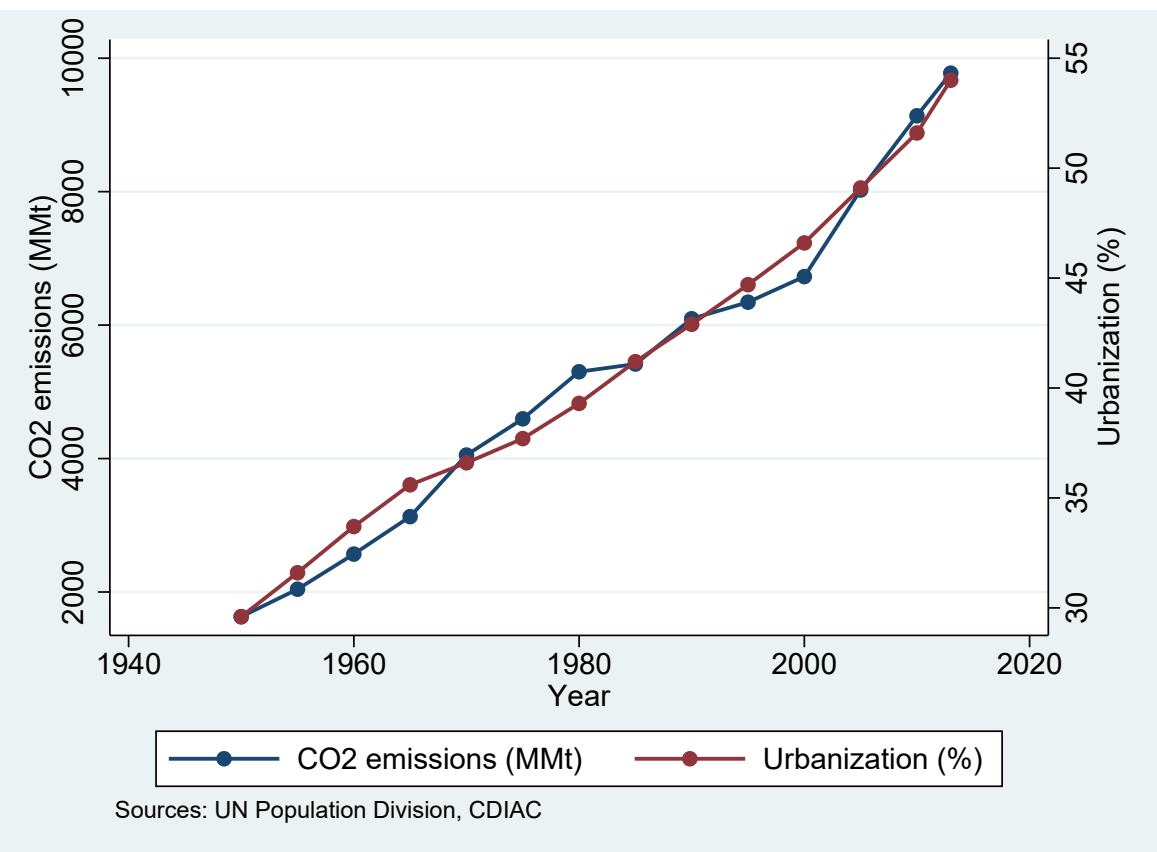

Figure 1: World urbanization and $\mathrm{CO}_{2}$ emissions 


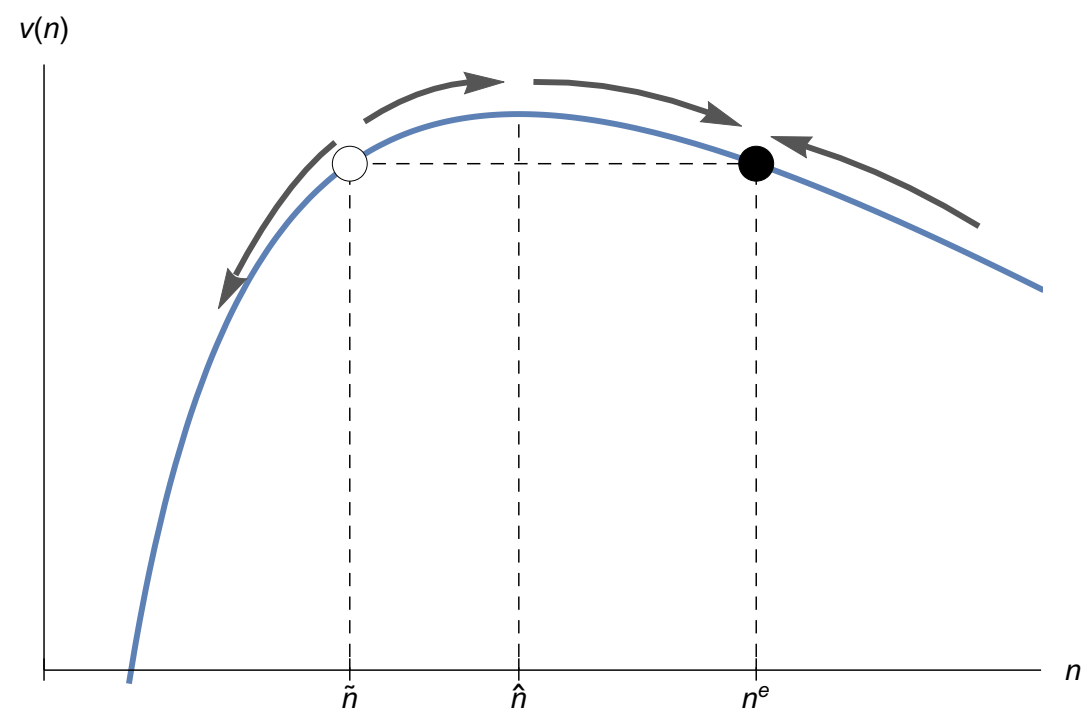

Figure 2: Equilibrium city size

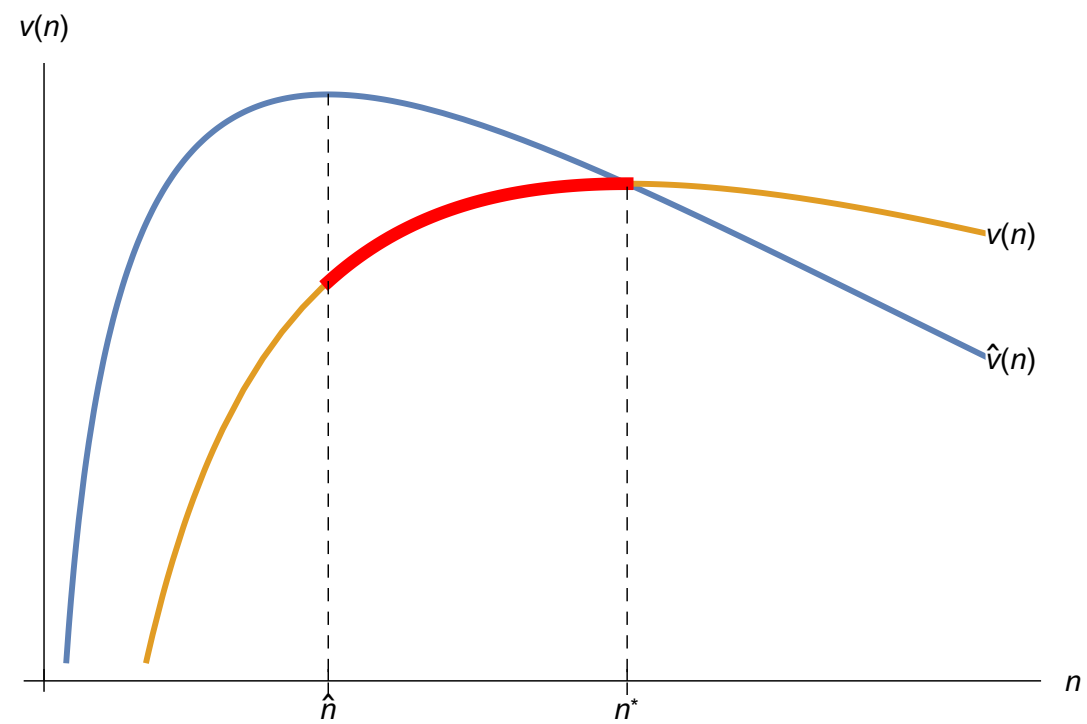

Figure 3: Equilibrium and optimum city size with global pollution 


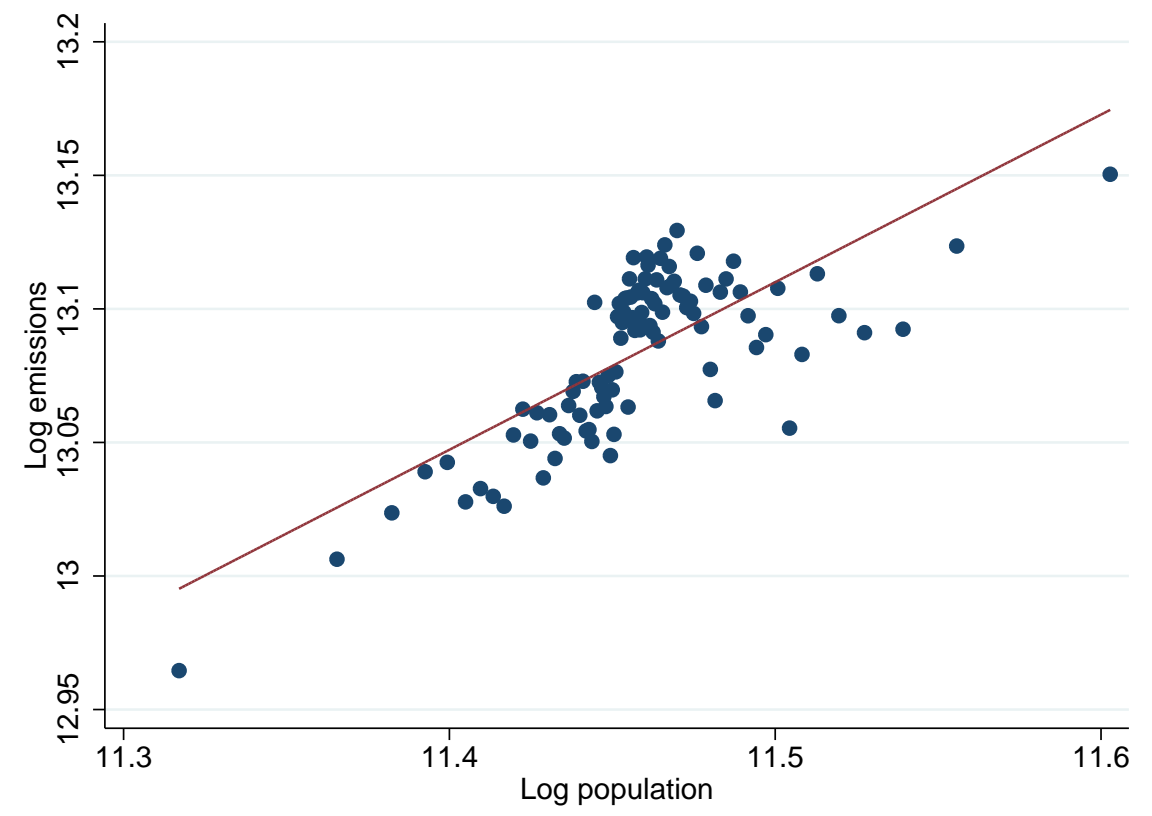

Figure 4: $\mathrm{CO}_{2}$-emissions and city size (Source: own calculations based on data from Fragkias et al. (2013)) 


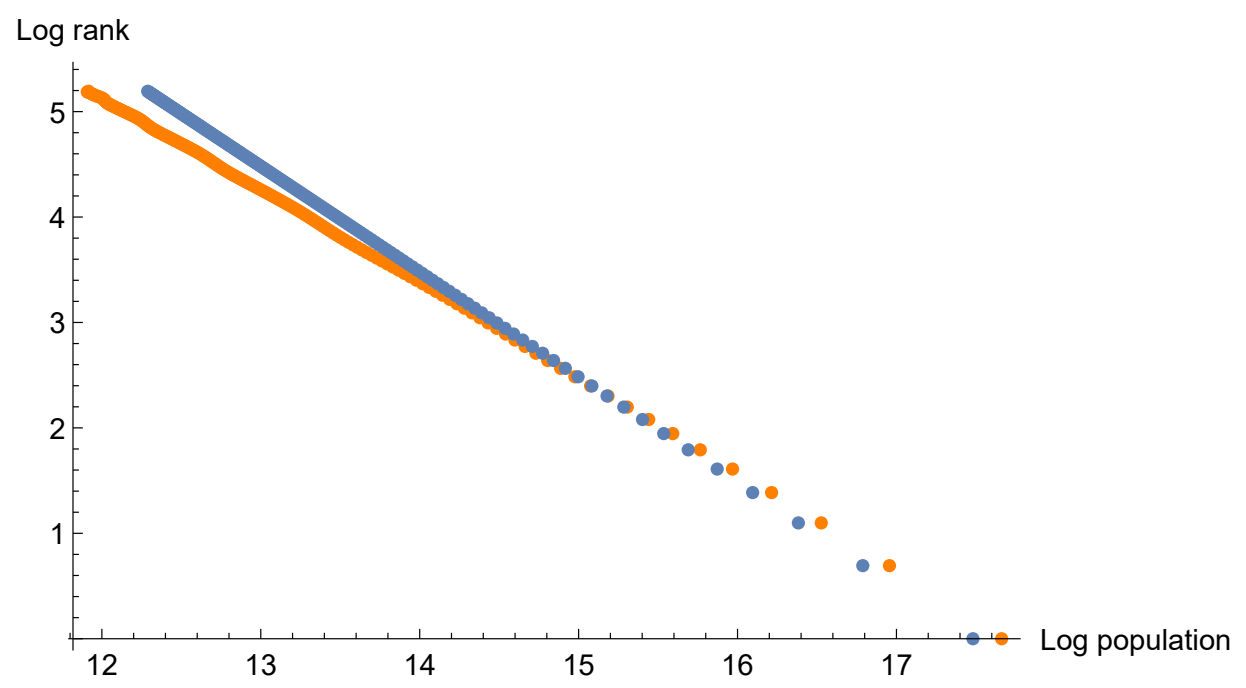

(a) Zipf's law

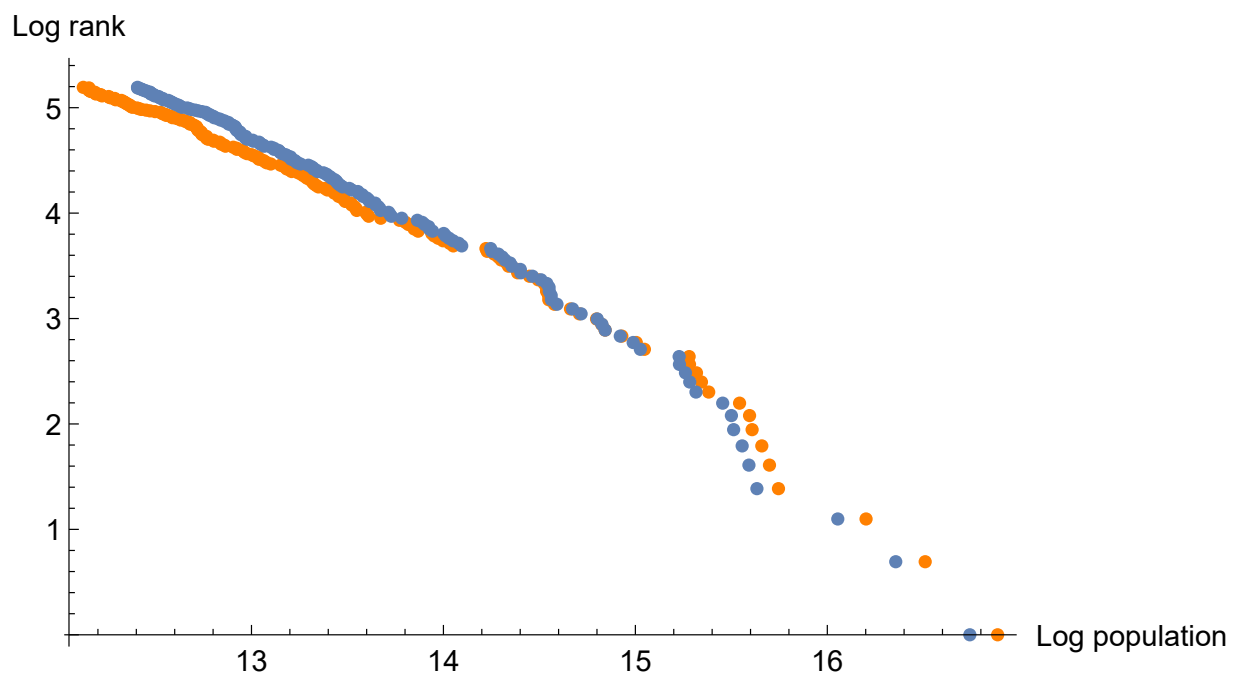

(b) Actual CBSA distribution

Figure 5: Optimal and equilibrium city size distributions(Source: own calculations based on data from Fragkias et al. (2013)) 